\title{
Humero-radial synostosis
}

INSERM

\section{Source}

INSERM. (1999). Orphanet: an online rare disease and orphan drug data base. Humeroradial synostosis. ORPHA:3265

Humero-radial synostosis is a rare, genetic, cong enital joint formation defect disorder characterized by uni- or bilateral fusion of the humerus and radius bones at the elbow level, with or without associated ulnar and carpal/metacarpal deficiency, leading to loss of elbow motion and, in many cases, functional arm incapacity. Bowing of radius may be additionally present. 